\title{
Enoturismo na região metropolitana de Curitiba: realidades e desafios de um novo território do vinho

\author{
Enrique Torres Bernier*
} \\ Universidad de Málaga (España)
}

\author{
Vander Valduga** Wagner Otavio Gabardo*** \\ José Manoel Gonçalves Gândara***** \\ Universidade Federal do Paraná (Brasil)
}

\begin{abstract}
Resumo: O vinho é patrimônio mundial e seu contexto de produção gera demanda turística nas regiões vinícolas mundiais. Este trabalho analisou a realidade da oferta e da demanda do enoturismo na região metropolitana de Curitiba, Paraná, Brasil. O estudo, que envolveu 7 empresas, fez uso de observação, questionário, grupo focal e análise de reputação online. Entre os principais resultados, constatou-se que as vinícolas analisadas constituem um grupo heterogêneo quanto a antiguidade, volume de produção e oferta de estruturas de apoio ao enoturismo. Para todas, o enoturismo revela-se crucial para a prospecção comercial. Os problemas mais evidentes relacionam-se a formação profissional, questões institucionais e de organização. Demanda, comercialização e criação de novos produtos ainda não são prioridade aos envolvidos. A demanda do enoturismo tem características regionais, com gastos distribuídos entre a participação em eventos do calendário vitivinícola, visitas guiadas e experiências gastronômicas, que se destacaram entre os itens analisados.
\end{abstract}

Palavras-chave: Turismo; Enoturismo; Oferta turística; Demanda turística; Curitiba; Brasil.

Wine tourism in greater Curitiba: the realities and challenges faced by a new wine region.

Abstract: Wine is part of world heritage and the wine-making regions usually attract tourism, as a result. This study is an analysis of the demand for the wine tourism on offer in Greater Curitiba, Paraná, Brazil. Seven wineries were studied using participant observation, questionnaires, focus group and analysis of online reputation. Among The main results of this heterogeneous group of wineries, of different ages, sizes and support structures for enotourism was that enotourism was essential for their commercial success.. The most evident problems have to do with vocational training and professional staff besides institutional and organisational issues.. Since the wine tourism demand is mostly regional at present, international commercialisation and roll-out of new products are not yet seen as priorities. Output on tourism is mainly centred on wine events, guided visits and gastronomic experiences.

Keywords: Tourism; Wine tourism; Tourism demand and supply; Curitiba; Brazil.

\section{Introdução}

O vinho constitui um produto agroalimentar de alto valor agregado (Elías, 2008) além ser um bem patrimonializado pela UNESCO (2013) como ingrediente basilar da dieta mediterrânea. Além da importância da atividade vitivinícola observada em países tradicionalmente vitivinicultores da Europa ocidental, a atividade expandiu suas fronteiras atlânticas e alcançou o continente americano, onde

\footnotetext{
* Universidad de Málaga (España); E-mail: ejtorres@uma.es

** Universidade Federal do Paraná (Brasil); E-mail: vandervalduga@gmail.com

*** Universidade Federal do Paraná (Brasil); E-mail: wgabardo@gmail.com

**** Universidade Federal do Paraná (Brasil); E-mail: jmggandara@yahoo.com.br
} 
desempenhou um papel histórico de desenvolvimento de regiões rurais como pode ser observado nos casos de Mendoza, na Argentina (Lacoste, 2013), no Chile (Briones Quiroz, 2006), Uruguai (Baptista, 2007) e no Brasil (Valduga, 2011).

Os interesses dos consumidores de vinho em conhecer as origens da bebida, os métodos de elaboração e sua cultura levaram ao surgimento do Enoturismo, uma das práticas do turismo cultural que conjugam prazer e saber, conhecimento e afetividade despertados pela degustação do vinho, das paisagens do seu entorno (Elias, 2008, 2014; Lavandoski \& Lanzer, 2008; Díaz Armas, 2008; González Morales, Ojeda \& Hernández Torres, 2015) e da cultura da comunidade anfitriã expressa no modo de vida (Daher, 2015) e na enogastronomia (Nowak \& Newton, 2006; Alonso \& Liu, 2011; Silva, Etges \& Valduga, 2016). Constitui um fenômeno amplo que valoriza um território, o saber fazer dos seus habitantes, além de provocar estímulos organolépticos múltiplos (Valduga, 2007). Trata-se efetivamente da constituição de territórios do vinho, que comportam saberes, fazeres, paisagens e outros vetores territoriais como o turismo (Elías, 2008; Sequeira \& Diniz, 2011; Valduga, 2014; Salvado, 2017).

Para a comunidade anfitriã, atores cruciais no processo, o enoturismo propicia pluriatividade ao viticultor, que passa a receber visitantes e com isso a possibilidade de comercializar sua produção e incrementar seus ingressos. No entanto, para que um destino de enoturismo de desenvolva é necessária a soma de diversos fatores que o impulsionem. Um território caraterizado pela cultural vínica que contemple uma concentração de vinícolas com infraestrutura para receber os visitantes mostra-se crucial.

No caso brasileiro, estudos sobre o desenvolvimento territorial de regiões vinícolas e do enoturismo concentram-se na Serra Gaúcha onde esta atividade decorreu em consequência da prosperidade da vitivinicultura (Valduga, 2011) permitindo que a região recebesse a primeira indicação geográfica de vinhos no Brasil (Falcade, 2011), elaborada a partir de critérios técnicos e culturais, espelhados no modelo europeu.

Em paralelo, trabalhos sobre outras regiões vitivinicultoras brasileiras demonstram que o processo de desenvolvimento responde à uma lógica inversa a da Serra Gaúcha. Enquanto na Serra, a atividade vitivinícola demonstra-se indutora do desenvolvimento regional e do enoturismo, em outras regiões o enoturismo se apresenta como estratégia primordial de desenvolvimento de um novo polo viticultor e de uma ressignificação do espaço rural, como observado na Serra Catarinense (Losso, 2010; 2016), na Campanha Gaúcha (Flores, 2011; Barbosa et al, 2017) e no Vale do Rio São Francisco (Galvão, 2006).

O Paraná, estado pertencente à região sul do Brasil, passou recentemente por um processo no qual novos atores iniciaram investimentos em projetos de vinícolas, implantação de vinhedos e estrutura de enoturismo nas zonas rurais da Região Metropolitana de Curitiba, a maioria com menos de uma década de existência. Estudos dedicados à análise desse processo ainda são incipientes, portanto, se fazem necessários para a compreensão desses mecanismos de transformação territorial. Para isso, parte-se da seguinte questão de pesquisa: qual é a realidade da oferta e da demanda do enoturismo na região metropolitana de Curitiba, Paraná, Brasil?

O objetivo deste trabalho é caracterizar a oferta e a demanda de enoturismo das vinícolas da Região Metropolitana de Curitiba (RMC). Especificamente, objetiva-se analisar a oferta enogastronômica como suporte às atividades de enoturismo e a organização da atividade enoturística do ponto de vista institucional na RMC. Como terceiro objetivo específico, na busca por atender a carência de estudos de perfil de demanda apontado por Áurea Vieira et al (2013) que ofereça a possibilidade comparativa de interesses de enoturistas de diferentes países como Austrália (Chartes \& Ali Knight 2001; 2002; Bruwer, 2004), Espanha (Rodríguez et al, 2013) e outras regiões do Brasil (Zanini, 2007; Lavandoski \& Lanzer 2008), propõe-se realizar uma caraterização inicial dos interesses dos enoturistas a partir de uma análise de comentários e fotografias de visitas feitas em vinícolas da RMC registradas na plataforma on line TripAdvisor. A análise encontra-se em sintonia com o levantamento de comportamentos de consumidor a partir da análise de dados publicados por usuários de redes sociais (Silva et al 2016; Feger et al, 2016; Silva \& Gândara, 2016).

$\mathrm{O}$ estudo torna-se relevante na medida em que traz à tona uma região emergente que passou a compor o cenário da vitivinicultura e enoturismo nacional. Trabalhos dedicados à região retratam vinícolas isoladamente e com olhares pontuais: é o caso do resgate de patrimônio industrial em meio a área de proteção ambiental para maturação de espumantes, a Cave Colinas de Pedra (Valduga \& Medeiros, 2013); e a Festa da Colheita da Vinícola Araucária entendida como tradição encenada para o enoturismo (Gabardo \& Valduga, 2017).

Todavia há outras vinícolas que integram a região e uma análise que englobe uma amostra ampla permitirá um maior entendimento da oferta disponível e os desafios a serem superados. Para tanto realizou-se, também, um levantamento detalhado dos aspectos relativos à oferta das vinícolas da 
Região Metropolitana de Curitiba -RMC e associadas a VINOPAR - Associação de vitivinicultores do Paraná - que reúne produtores com produção regulamentada. A associação foi fundada em 2016 e possuía sete integrantes no momento de realização da pesquisa (2017), sendo que apenas uma delas optou por não participar da pesquisa.

\section{O enoturismo como produto turístico}

Os estudos sobre o enoturismo são relativamente recentes, internacionalmente datam do início dos anos 1990. A expansão da produção científica sobre o assunto segue acompanhada pelo aumento da oferta turística e estabelecimento de novas regiões vinícolas. A Carta Europeia de Enoturismo de 2015 define o Enoturismo como o desenvolvimento das atividades turísticas, de ócio e tempo livre, dedicadas ao descobrimento e desfrute cultural e enológico da vinha, do vinho e seu território. Para Hall et al., (2004, p. 3), "o enoturismo pode ser definido como visitações a vinhedos, vinícolas, festivais de vinhos e vivenciar na prática as características de uma região de uvas e vinhos". Para Lacoste el al (2011, p. 43) "el principal objetivo del enoturismo es activar los sentidos y las emociones del visitante: la visita a la viña tiene que convertirse en un acontecimiento especial". Segundo Elias (2008) o enoturismo constitui uma ferramenta de valorização do patrimônio vitivinícola e a preservação das paisagens culturais do vinhedo é condição sine qua non ao fomento da atividade. Para Valduga (2012) o enoturismo pressupõe o deslocamento de pessoas, motivadas pelas propriedades organolépticas e por todo o contexto da degustação e elaboração de vinhos, bem como a apreciação das tradições, cultura, gastronomia e tipicidade dos territórios do vinho. É um fenômeno dotado de subjetividade em que a principal substância é o encontro com quem produz uvas e vinhos.

Mitchel \& Hall (2006) agrupam em temas centrais as investigações científicas sobre enoturismo tais como: o produto enoturístico, caracterizando as vinícolas, rotas e festivais do vinho; o impacto socioeconômico do enoturismo no desenvolvimento regional sobretudo de áreas rurais; e os aspectos relativos à demanda de visitantes, buscando quantificá-la e qualificá-la ao analisar o comportamento dos visitantes, seu perfil sócio-demográfico, motivações e satisfações com a experiência em um território do vinho.

$\mathrm{Na}$ Espanha, no tangente ao produto enoturístico, o desenho de rotas do vinho mostra-se uma prioridade com a criação da Associação Espanhola de Cidades do Vinho (ACEVIN) em 1994. Segundo López-Guzmán et al (2013) em 2000, no bojo do plano de qualidade do turismo espanhol de 2000-2006, é proposto o produto turístico Rutas del Vino de España que sistematiza uma série de requisitos a serem certificados para a consolidação de uma rota do vinho: os aspectos de planejamento e gestão da rota; os recursos territoriais do destino que viabilizem a atividade como infraestrutura e sinalização; o posicionamento e a comercialização do produto no mercado; os serviços turísticos de apoio como agências, meios de hospedagem e alimentação; e a estrutura individual de cada vinícola para recepção e entretenimento dos visitantes. Segundo a ACEVIN (2014) o objetivo de uma rota do vinho é incentivar o turismo cultural em destinos rurais, apoiado nas "actividades vitícolas, gastronómicas y culturales, acompañado por una amplia oferta de alojamiento con servicios relacionados con dicha actividad (bodegas, enotecas, vinotecas, museos del vino), así como de una amplia oferta de actividades complementarias" (p. 1). Foi criado, então, o observatório turístico das rotas visando monitorar seus desempenhos (López-Guzmán et al, 2014). Surgem, a posteriori, estudos de caso que buscam caracterizar e avaliar as rotas criadas em território espanhol como a do Marco de Jerez (Sánchez, 2010), Bierzo (del Rio Rama et al, 2013), Montilla-Moriles (López-Guzmán \& Cañizares, 2008) e Penedés (Medina \& Tresserras, 2008) entre outras. Frente ao êxito observado nos casos espanhóis, foi então criada a Rede Européia de Cidades do Vinho (RECEVIN) com o intuito de avaliar e implementar estratégias de consolidação de produtos enoturísticos ao longo do continente europeu (Escolar \& Morueco, 2011).

No Brasil, a literatura sobre o tema não é muito ampla, apesar de sua expansão nos últimos dez anos e ela segue, igualmente, o desenvolvimento das novas regiões vitícolas do país, com muitas pesquisas caracterizadas como estudos de caso. Contudo, independente da procedência, estudos importantes têm sido publicados em diversas vertentes, além dos já citados: do ponto de vista evolutivo em regiões vinícolas, do território, cooperação e do patrimônio do vinho (Alonso, Sheridan \& Scherres, 2008; Alonso, 2009; Alonso \& Liu, 2011; Alonso \& Liu, 2012; Valduga, 2014; Tomazzoni, Valduga \& Ashton, 2016; Salvagni, Valduga \& Nodari, 2017; Salvado, 2017); na perspectiva de roteirização, destinos turísticos, planejamento e imagem (Fuller, 1997; Getz, 2000; Williams, 2001; Bruwer, 2003; Sanders, 2004; Hojman \& Jones, 2012; Sartori, Mottironi e Corigliano, 2012; Álvarez García et al, 2014; Castro, 2017); e da 
perspectiva da demanda, gestão das organizações e do marketing no turismo do vinho (Leiper \& Carlsen, 1998; Getz et al., 1999; Hall et al, 2004; Brow \& Getz, 2005; Bruwer \& Alant, 2009; Simeon \& Sayeed, 2011; Marzo Navarro \& Pedraja Iglesias, 2012; Quadri-Felitti \& Fiore, 2012; Matellanes Lazo, 2014, Silva, 2016; Lavandoski et al, 2017).

No que se refere à demanda turística, ela é constituída pelas características pessoais dos turistas: motivações, percepções, experiências prévias e expectativas (Paglod, 2011). Nesse contexto, pode-se dizer que os turistas buscam novas formas de consumo turístico que tenham a capacidade de gerar experiências memoráveis. No conjunto de abordagens pela via experiencial, ganham corpo as pesquisas em enoturismo, muitas delas fundamentadas nos estudos da chamada Economia da Experiência de Pine II e Gilmore (1998). Algumas delas vertem para ao lado emocional da demanda do enoturismo, para o planejamento de experiências, sensações, criatividade e inovação (Ali-Knight \& Carlsen, 2003; Carmichael, 2005; Nowak \& Newton, 2006; Roberts \& Sparks, 2006; Asero \& Patti, 2009; Tonini \& Lavandoski, 2011; Quadri-Felitti \& Fiore, 2012; Capitello, Begalli \& Agnoli, 2013; Bizinelli et al, 2014; Gravari-Barbas, 2014; Galvéz, Fernández e Lopez-Guzmán, 2015; Silva \& Gândara, 2016, Manosso et al, 2016). Diante do exposto, pela periodização das fontes bibliográficas, pode-se sugerir que os estudos em enoturismo avançaram de um contexto amplamente descritivo da atividade nos anos 1990, abordando casos aplicados e de planejamento de rotas e roteiros e estudos de demandas para contextos mais simbólicos e experienciais, sejam da oferta, sejam da demanda em enoturismo. Pode-se dizer, ainda, que os estudos de enoturismo no contexto atual abordam aspectos de inovação (Hall, 2009) em distintos contextos, como na política, no uso de tecnologia ou na formação de redes e cluster (Guthey, 2008) para a atividade.

O enoturismo é uma prática consolidada de turismo nas regiões vinícolas mundiais e segue alguns protocolos de poucas variações em suas estruturas fundamentais. Ricolfe et al (2010) identificam, através de revisão bibliográfica, quais atividades de enoturismo são as mais citadas na literatura e constituem interesse motivador dos enoturistas: comprar vinho, degustar o vinho na vinícola, receber informações sobre o vinho e seu processo de elaboração, visitar uma vinícola, visitar seu vinhedo, participar de feiras ou festas do vinho, comer na vinícola, visitar um museu do vinho, visitar sítios naturais da região, fazer amigos, visitar monumentos entre outros.

Sobre o perfil da demanda, Charters \& Ali-Knight (2002) ao investigar o hábito de enoturistas de vinícolas australianas, propõem quatro níveis de turistas a partir do interesse e conhecimento sobre vinhos: novatos, interessados, amantes do vinho e connoisseurs. Os autores identificam que, independente do envolvimento com o vinho, a maioria dos enoturistas valoriza o ambiente/“cenário" da vinícola e a aquisição de novos conhecimentos durante uma visita guiada que necessariamente inclua a degustação de vinhos de boa qualidade. Os autores enfatizam a importância das visitas guiadas como ferramenta de aprendizado da cultura vínica e fidelização do consumidor.

Cabe destacar ainda o trabalho de Alant \& Bruwer (2004) com visitantes das regiões australianas Maclaren valley e Coonawarra. Os autores expõem que a natureza da experiência em enoturismo é composta de três dimensões principais: o visitante - seu perfil sócio demográfico, estilo de vida e hábitos de consumo de vinho - a região - com suas rotas, vinícolas, paisagem, atrações e produtos vínicos - e $a$ dinâmica da visita - se esta é inédita ou há experiências prévias e quais são as motivações e comportamentos. A partir da investigação de turistas australianos, os autores identificam que o prazer em degustar vinhos, descobrir vinhos especiais e únicos e poder adquiri-los diretamente na vinícola são as experiências mais desejadas entre visitantes iniciantes e reincidentes. Concluem que o contexto do enoturismo estaria relacionado a prazer e relaxamento.

Alonso, Sheridan \& Scherrer (2008) destacam a importância da sala de degustação de vinhos como o lugar que consolida a experiência de visita às vinícolas nas Ilhas Canárias, Espanha. Os autores concluem que a experiência da degustação é crucial para a divulgação dos produtos, formação e fidelização dos clientes que criam empatia pela vinícola visitada.

Gávez, Fernández \& López-Guzmán (2015) ao analisar a motivação e satisfação de visitantes de um festival de vinhos de Montilla-Moriles, Espanha, identificam que o grau de satisfação da visita aumenta entre aqueles com interesse pontual em desfrutar dos sabores da enogastronomia regional, seguido por aqueles que assistem aos festivais em busca de entretenimento e prazer. Já Lavandoski \& Lanzer (2008), a partir da análise de fotografias constataram que o vinhedo tem um forte apelo na experiência do enoturismo, com inúmeros registros de vinhedos. A paisagem do vinhedo constituiria, portanto, um elemento legitimador da experiência em enoturismo.

A partir dos autores citados, observa-se, portanto, que as estruturas mínimas de oferta de enoturismo, como visitas guiadas e degustações dirigidas, a oferta de enogastronomia, as paisagens rurais do entorno 
com eventuais vinhedos integrados à propriedade são aspectos que chamam a atenção e são valorizados pelos enoturistas. É precisamente nesse contexto, que se pretende analisar o conjunto da oferta e da demanda do enoturismo na Região Metropolitana de Curitiba, conforme será visto a seguir.

\section{Metodologia}

Esta pesquisa se caracteriza com um estudo de natureza qualitativa com revisão bibliográfica sobre o enoturismo e enogastronomia que amparem teoricamente os objetivos aqui propostos. Em seguida, a equipe de pesquisa visitou em diferentes dias as sete empresas vitivinícolas que compõe a VINOPAR, participando das atividades de enoturismo propostas por cada uma delas e, na sequencia, entrevistando os seus proprietários ou gerentes. Desta maneira obteve-se impressão in loco das instalações, situação e problemática de cada uma das empresas e do conjunto das mesmas através de observação participante (Alonso, 2016).

Posteriormente foi elaborado e distribuído um questionário estruturado orientado a analisar os aspectos mais importantes de cada empresa, como suas características societárias, sua oferta enogastronômica, tipos de vinhos que produzem e seu destino comercial, comida oferecida (quando aplicável), formação de recursos humanos e investimentos em tecnologias. Igualmente, analisou-se as relações das empresas com a VINOPAR enquanto projeto conjunto e as características do roteiro, especialmente referentes à paisagem, bem como os aspectos comerciais, de captação e de fidelização de clientes.

Finalmente, realizou-se um grupo focal com base em Almeida (2016), do qual participaram os responsáveis das sete empresas que compõem a VINOPAR. Foram elencados, com base nas informações obtidas nas etapas anteriores, temas para a interação discursiva dos participantes sobre desafios e melhorias da associação e solicitou-se que ponderassem o grau de importância e urgência de cada tema.

Em paralelo, com o intuito de caracterizar preliminarmente a reputação on line das vinícolas perante os visitantes, realizou-se uma pesquisa na plataforma colaborativa de informações turísticas TripAdvisor usando a técnica de análise de conteúdo de Lima (2003). Buscou-se a essência e o teor dos comentários junto à análise de imagem de fotografias carregadas pelos usuários que visitaram as vinícolas. Foram analisados 550 fotografias e 483 comentários de cinco vinícolas que possuíam um perfil ativo nesta rede social e agrupados em seis categorias que sublinhavam: aspectos da paisagem; da vinícola; da experiência gastronômica; dos vinhos; do vinhedo e de outros. Os comentários, além de categorizados de tal maneira, foram classificados entre positivos ou negativos. A pesquisa foi realizada entre abril e setembro de 2017. O quadro 1 sintetiza as etapas metodológicas utilizadas para a realização da pesquisa.

\section{Quadro 1: Síntese metodológica da pesquisa}

\begin{tabular}{|l|l|l|}
\hline Etapas da pesquisa & \multicolumn{1}{|c|}{ Metodologia } & \multicolumn{1}{c|}{ Amostra } \\
\hline $1^{\circ}$ & $\begin{array}{l}\text { Visita as vinícolas da Vinopar e } \\
\text { participação nas atividades de } \\
\text { enoturismo com observação }\end{array}$ & 7 (sete) \\
\hline $2^{\circ}$ & Entrevista aos gerentes após as visitas & 7 (sete) \\
\hline $3^{\circ}$ & $\begin{array}{l}\text { Questionário estruturado enviado as } \\
\text { empresas }\end{array}$ & 7 (sete) \\
\hline $4^{\circ}$ & Grupo focal com os gerentes & 7 (sete) \\
\hline $5^{\circ}$ & $\begin{array}{l}\text { Reputação on line com análise de } \\
\text { conteúdo }\end{array}$ & $\begin{array}{l}550 \text { fotografias e } 483 \text { comentários } \\
\text { de } 5 \text { (cinco) vinícolas }\end{array}$ \\
\hline
\end{tabular}

Fonte: Os autores (2018)

\section{Os antecedentes do enoturismo na RMC}

A RMC, constituída em 1974, cresceu de 14 a 29 municípios desde então e é considerada a quinta região economicamente mais relevante e o terceiro polo automotivo do Brasil. Quatro dos dez maiores Produtos Internos Brutos do Estado pertencem à municípios da região, liderados por Curitiba e São 
José dos Pinhais. Cerca de $45 \%$ do seu território possui restrições legais e ambientais por tratar-se de área de mananciais de água, o que limita a proliferação industrial e favorece a manutenção de áreas rurais (COMEC, 2017). Curitiba é considerado pelo mapa do turismo brasileiro um destino indutor A, capaz de potencializar o desenvolvimento turístico da RMC e dezesseis de seus municípios compõem a denominada Rota do Pinhão dentro do programa de regionalização do turismo do ministério do turismo federal (Ministério, 2013).

A RMC está localizada no primeiro planalto paranaense com altitude média em torno de 934 metros. Banhada pelas nascentes do rio Iguaçu, faz divisa com a Serra do Mar à leste - que a separa do litoral do estado - escarpa devoniana a oeste - que demarca os limites com o segundo planalto - e se estende de norte a sul fazendo divisa interestadual com São Paulo e Santa Catarina. (COMEC, 2017). Possui clima temperado úmido e concentra as temperaturas médias mais baixas entre as regiões metropolitanas brasileiras (SIMEPAR, 2018).

Os antecedentes da produção de vinhos na RMC estão associados à vinda de imigrantes de origem italiana no fim do século XIX que se dedicaram ao cultivo de uvas do tipo labrusca e a elaboração de vinhos de mesa, conhecidos popularmente como vinhos coloniais (Santos, 1999). Entretanto, pragas de solo que se alastraram pelos vinhedos e infestaram as vinhas na década de 1990 desestimularam os habitantes a seguir cultivando uvas e muitos optaram por trazer o vinho feito em outras regiões do sul do Brasil (Brandenburg, 2018). Anterior ao surgimento da VINOPAR, escopo desta pesquisa, duas regiões se conformaram como focos de uma oferta turística associados à italianidade que dialogam de certa forma com o enoturismo: o bairro curitibano Santa Felicidade e a Colônia Mergulhão em São José dos Pinhais.

No noroeste da capital paranaense, o bairro Santa Felicidade manteve o legado da cultura italiana através da gastronomia, expressa na concentração de dezenas de restaurantes que oferecem rodízio de pratos protagonizados pela polenta, risoto, frango assado e salada de radicchi (almeirão verde) acompanhados de vinho de mesa (Féder, 2005). O bairro veio a caracterizar-se como um destino de interesse gastronômico com enfoque na comida típica oriunda do nordeste da Itália adaptada aos costumes brasileiros. E o vinho tornou-se um adereço desta oferta.

Em município vizinho, se estabeleceram na zona rural de São José dos Pinhais, na Colônia Mergulhão, região que passou a sediar um circuito de turismo rural denominado Caminhos do Vinho (Nitsche \& Neri, 2014), composta por estabelecimento de comercio de alimentos e bebidas, chácaras com restaurantes e atividades de lazer ressignificando os labores rurais ao atribuir-lhes uso turístico e de entretenimento. $\mathrm{O}$ almoço típico ali servido caracteriza-se pelo sistema buffet com cardápio variado que mescla pratos da cozinha paranaense com influências da cozinha dos imigrantes poloneses e italianos. A despeito do nome "Caminhos do Vinho", o circuito não se caracteriza como uma rota de enoturismo propriamente dita pois não incluiu vinhedos como parte da paisagem ou visitas guiadas em torno da produção de vinhos. A visita às supostas "vinícolas" restringe-se a um contato comercial de degustação e venda de vinhos coloniais, muitos deles produzidos e engarrafados em estados vizinhos. Tal panorama contradiz a proposição do vínculo do vinho ao território e da paisagem vitícola como representação de um espaço, condições primordiais do enoturismo (Falcade, 2011; Sequeira \& Diniz, 2011; Valduga, 2011; Álvarez García et al, 2014; Gravari-Barbas, 2014; González Morales, Ojeda \& Hernández Torres, 2015; Salvado, 2017).

A retomada da produção vitivinícola e a implantação de vinhedos de variedades viníferas se daria somente na virada do século XXI, seguida pelo investimento em estruturas e atividades de enoturismo. A fundação da VINOPAR - Associação de Vitivinicultores do Paraná - se deu apenas em 2016, quando 7 vinícolas se reuniram com o objetivo de fortalecer a divulgação de seus vinhos e seus empreendimentos, semeando assim, o enoturismo na RMC conforme será visto no próximo tópico.

\section{VINOPAR e o enoturismo na RMC}

A VINOPAR carateriza-se por um perfil heterogêneo de integrantes relativamente dispersos territorialmente na RMC. São duas vinícolas no município de Campo Largo, uma no município de Colombo, uma no município de Quatro Barras, duas no município de Piraquara, uma em São José dos Pinhais e uma no bairro curitibano Santa Felicidade. Das duas vinícolas de Piraquara, uma delas, a Copasol-Trentina, que é uma cooperativa agroalimentar com poucos produtos vinícolas optou por não participar do estudo, portanto não integra este trabalho. Não constituem o único núcleo de vinicultores do estado, que também apresenta focos no interior do Paraná, como pode ser observado no mapa 1, mas são o recorte da análise aqui pretendida. 
Quadro 2: Vinícolas da RMC pertencentes à VINOPAR.

\begin{tabular}{|c|c|c|c|c|}
\hline Vinícola & Município & Fundação & $\begin{array}{c}\text { Produção média } \\
\text { anual vinho finos }\end{array}$ & $\begin{array}{c}\text { Produção média } \\
\text { anual vinhos de } \\
\text { mesa }\end{array}$ \\
\hline Araucária & $\begin{array}{c}\text { São José dos } \\
\text { Pinhais }\end{array}$ & 2007 & 35000 & 0 \\
\hline Colinas de Pedra & Piraquara & 2013 & 4500 & 0 \\
\hline Família Fardo & Quatro Barras & 2008 & 37800 & 4000 \\
\hline Família Zanlorenzi & Campo Largo & 1940 & 645000 & 11 milhões \\
\hline Franco Italiano & Colombo & 1973 & 35000 & 40000 \\
\hline Legado & Campo Largo & 1998 & 11000 & 0 \\
\hline Santa Felicidade & Curitiba & 1967 & 4500 & 1,2 milhões \\
\hline
\end{tabular}

Fonte: Os autores (2018) Mapa 1: Localização dos municípios com produção de uvas e/ou vinhos
no PR e aqueles pertencentes à VINOPAR na RMC (em verde)
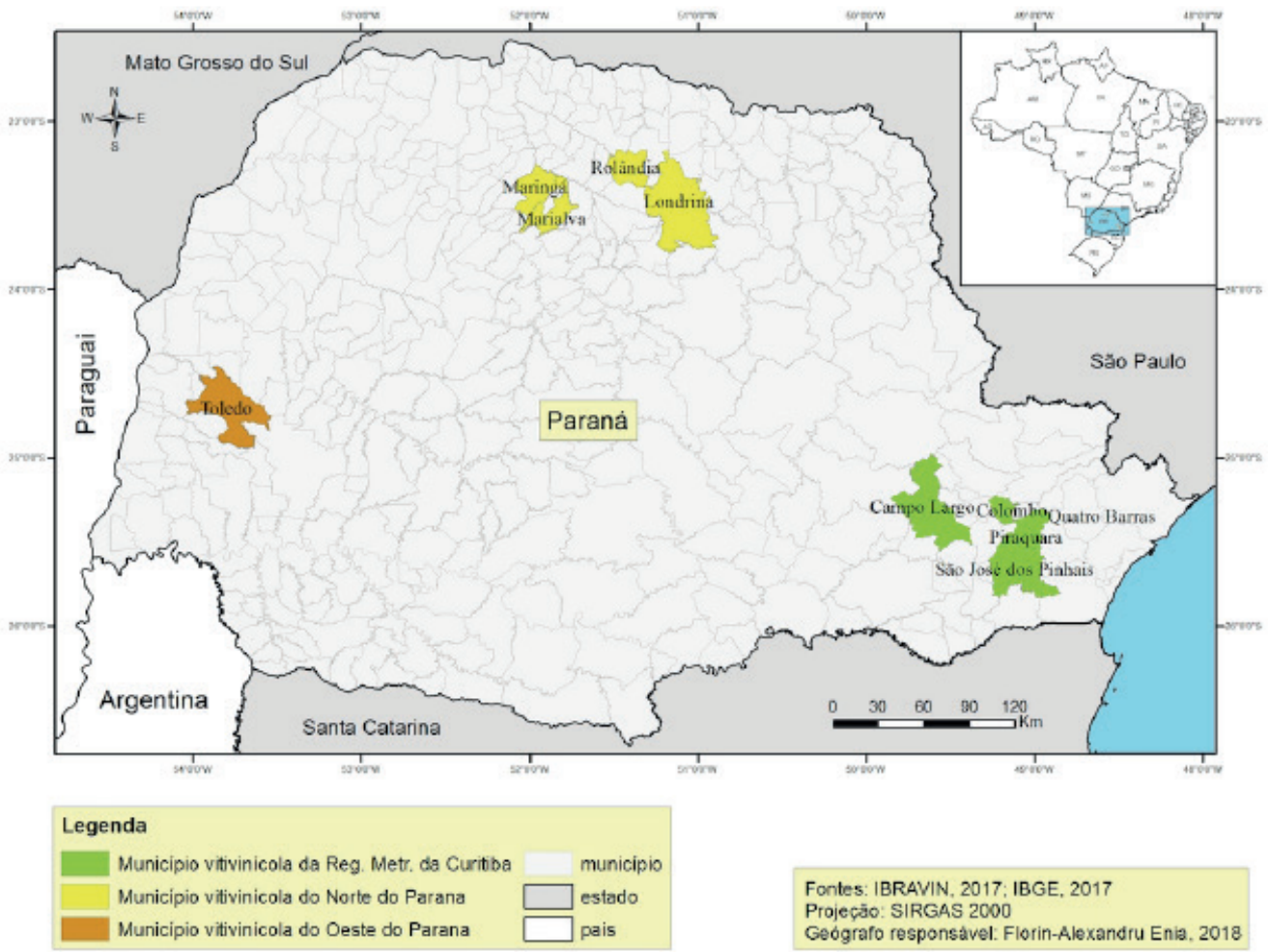

A dispersão territorial impede que as vinícolas possam ser acessadas em um único dia, tampouco há uma sinalização padronizada que permita transitar de uma vinícola a outra, como se observou durante as visitas de campo. Não se caracteriza, portanto, como uma rota de vinhos nos modelos tradicionais, mas um conjunto de empresas pulverizadas pela RMC cujo denominador comum é seu eixo temático, o vinho. Ainda assim pode-se considerar um território do vinho em processo de instauração (Elías, 2008; Sequeira \& Diniz, 2011; Valduga, 2014; Salvado, 2017), uma vez que a atividade apresenta-se como significativa no contexto. 
Baseado nas informações obtidas através dos questionários, tratam-se de empresas jovens, com pouco mais de de dez anos de existência cujas atividades de enoturismo são ainda mais recentes - a exceção da Vinícola Santa Felicidade em Curitiba, fundada em 1967, e da Famiglia Zanlorenzi em Campo Largo, fundada na década de 1940 e a empresa de maior porte, focada no engarrafamento de sucos e vinhos de mesa com a produção de vinhos finos em menor escala, sem a oferta de experiências em enoturismo.

A maioria das empresas são familiares (5), duas empresas com gestão profissionalizada. O total de empregados é de 86, com a média de 11 empregados por empresa caraterizando-as como pequenas e médias. Sobre a formação desta mão-de-obra, 54\% possuem ensino médio, $20 \%$ ensino superior (dos quais $8 \%$ são pós-graduados) e 18\% ensino fundamental. Os cargos de gerência absorvem os funcionários mais graduados. Quatro possuem sommelier em seus quadros de funcionários. Quanto a capacitação, cinco vinícolas realizam treinamentos semestrais, uma delas anuais e outra não realiza.

Sobre a oferta de enoturismo, identificou-se a média de 3,8 dos funcionários que se dedicam a atender aos visitantes - o que representa $35,5 \%$ da mão-de-obra total. A atenção ao visitante acontece sobretudo nos finais de semana e feriados. Os serviços oferecidos em todos os empreendimentos são a venda de vinhos, produtos alimentares, acessórios e/ou souvenires, seguido de degustação de vinhos (6), visitas guiadas (5) pela vinícola e/ou vinhedo quando existente (2 vinícolas possuem vinhedos junto à propriedade e o incluem na visitação, Legado e Araucária).

Cinco possuem serviço de alimentação das quais três em restaurantes anexos, alimentos servidos com a degustação de vinhos com a intenção de harmonizá-los (1) e cestas de picnic para consumo nas áreas de lazer (1). Entre as que oferecem restaurantes, duas servem pelo sistema buffet e uma pelo $a$ la carte com um misto de pratos regionais e da cozinha internacional, com ênfase na italiana. No caso da vinícola Franco Italiano, as massas são oferecidas como destaque do menu de pratos; na Araucária há um acento em pratos elaborados com ingredientes do entorno que originam um cardápio de "comida campestre"; e na Cave Colina de Pedra, um buffet de pratos servidos em pequenas porções pensados na harmonização com os espumantes ali maturados e finalizados.

As visitas guiadas são oferecidas além do idioma português, em inglês e espanhol em casos pontuais de visita de turistas estrangeiros. Três vinícolas cobram por suas visitas guiadas e uma cobra segundo o tipo de experiência oferecida. As demais não cobram pela prestação dos seus serviços, no entanto não oferecem visitas guiadas, apenas degustação e venda de produtos.

Dentre outras atividades, duas oferecem a festa da colheita, onde os visitantes têm a oportunidade de colher uvas e participar de um ensaio de vinificação - na vinícola Legado - e da pisa-a-pé das uvas - na vinícola Araucária. Esta última promove o evento anual "sapecada de pinhão" - semente da árvore que batiza a vinícola - consumida nos meses de inverno após cozimento no calor de uma fogueira. A vinícola Legado promove eventos musicais esporádicos com bandas ao vivo acompanhados de vinhos e gastronomia. A Franco Italiano realiza aos sábados um breve curso educativo sobre vinhos a seus clientes. A Família Fardo realiza eventos enogastronômicos informais esporádicos onde se propõe a combinação de vinhos da vinícola com comidas de preparo rápido servidas por food trucks.

O Quadro 2 apresenta a síntese da oferta das vinícolas da Vinopar em 2018:

Quadro 2: Resumo da oferta em enoturismo da VINOPAR.

\begin{tabular}{|c|c|c|c|c|c|}
\hline Vinícola & $\begin{array}{c}\text { Vinhedos } \\
\text { produtivos } \\
\text { integrados à } \\
\text { propriedade }\end{array}$ & $\begin{array}{c}\text { Visita } \\
\text { guiada }\end{array}$ & $\begin{array}{c}\text { Oferta de } \\
\text { gastronomia } \\
\text { ou } \\
\text { restaurante } \\
\text { anexo }\end{array}$ & $\begin{array}{c}\text { Eventos } \\
\text { (gastronômicos, } \\
\text { festa da } \\
\text { vindima, } \\
\text { educativos) }\end{array}$ & $\begin{array}{c}\text { Varejo de } \\
\text { vinhos e } \\
\text { souvenires }\end{array}$ \\
\hline Araucária & Sim & Sim & Sim & Sim & Sim \\
\hline Colinas de Pedra & Não & Sim & Sim & Eventual & Sim \\
\hline Família Fardo & Não & Sim & Sim & Sim & Sim \\
\hline Família Zanlorenzi & Não & Não & Sim & Não & Sim \\
\hline Franco Italiano & Não & Sim & Sim & Sim & Sim \\
\hline Legado & Sim & Sim & Eventual & Sim & Sim \\
\hline Santa Felicidade & Não & Não & Não & Não & Sim \\
\hline
\end{tabular}

Fonte: Os autores (2018) 
Os eventos acima mencionados funcionam como estratégia de captação e manutenção de clientes e são em maioria divulgados pela pagina web própria das vinícolas e pelas redes sociais. Outras ferramentas de captação de novos enoturistas são a divulgação espontânea na imprensa escrita e televisionada, seguida pela reduzida sinalização em vias de tráfego de veículos e a participação de algumas das vinícolas em eventos de degustação de vinhos, de maneira isolada, ainda não em conjunto. Baseado em informações coletadas em entrevistas individuais durante visitas às vinícolas observou-se que quaisquer ações em parceria com agentes do trade turístico também ocorrem de forma individual. Como o caso da oferta de passeios por agências de receptivo da RMC, distribuição de material gráfico em postos de informações turísticas do aeroporto internacional de Curitiba, convênio com a operadora de passeios de serra Serra Verde e hotéis pontuais localizados no centro de Curitiba. Até o momento não foi desenhado uma estratégia conjunta da associação de promoção e captação de novos visitantes.

Da recente fundação da VINOPAR no final de 2016 até 2018 as ações desenvolvidas em conjunto ainda são escassas. A criação de um guia ilustrativo de vinícolas (figura 1), da marca da instituição (figura 2) e de uma página web reunindo as informações sobre histórico, vinhos produzidos e serviços de enoturismo ${ }^{1}$ (VINOPAR, 2018).

Figura 1: Guia ilustrativo das vinícolas da Vinopar (VINOPAR, 2018)

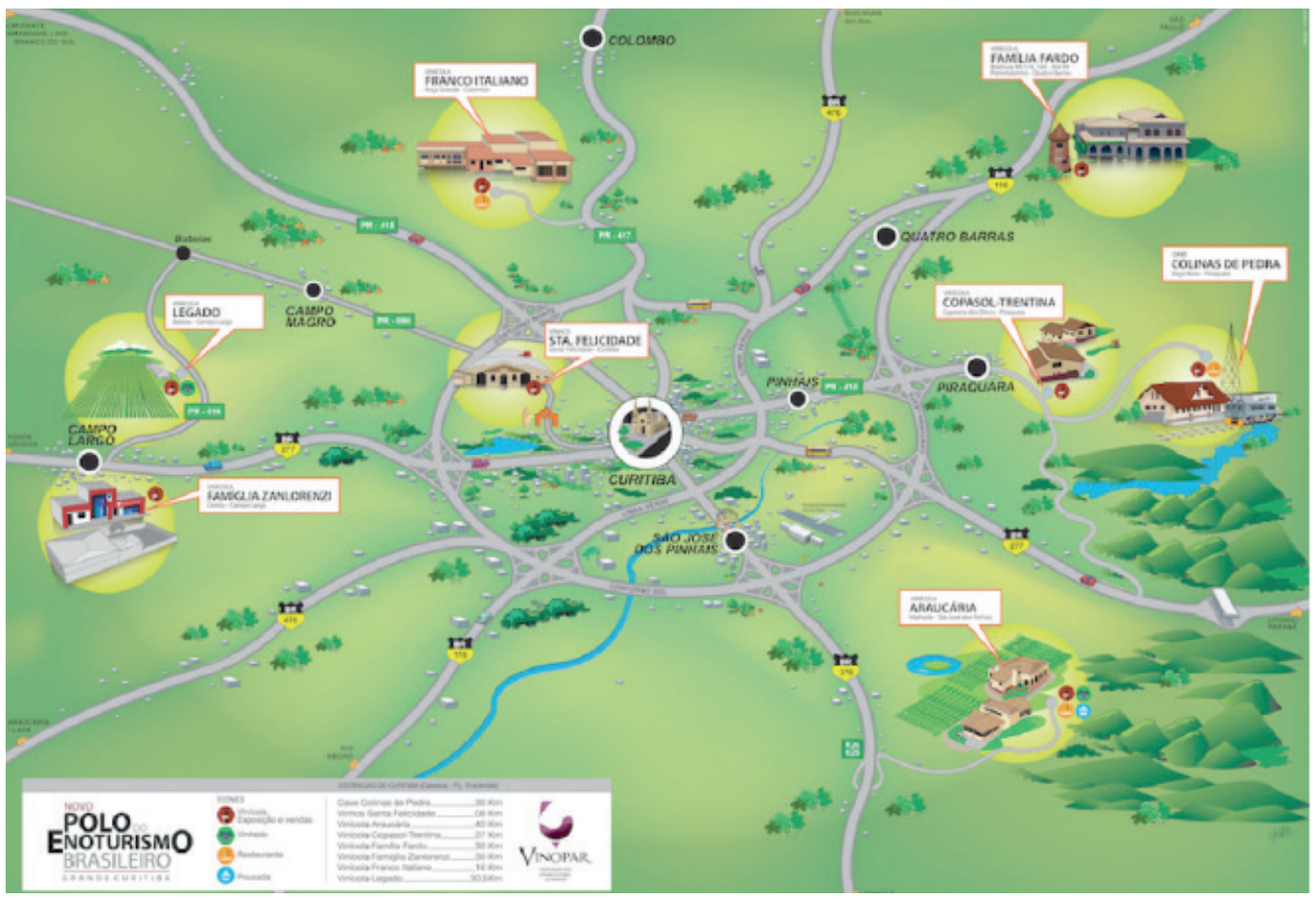

Conforme exposto, apenas a cooperativa Copasol-Trentina, que consta na figura um, optou por não participar do estudo em tela. A figura 2 mostra a logomarca da associação. 
Figura 2: logomarca da associação.

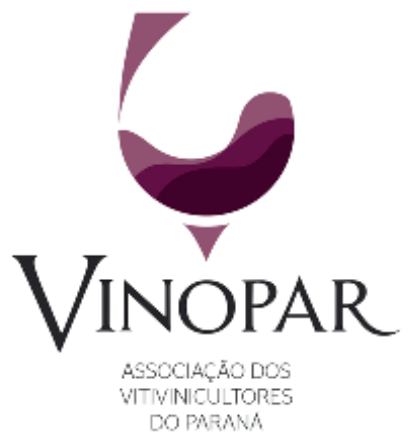

Tendo em vista que a maioria das vinícolas têm nas visitações à vinícola sua maior oportunidade de comercialização e divulgação de seus produtos - responde a cerca de 50\% do faturamento de quatro delas - desenvolver a promoção e enoturismo de maneira integrada apresenta-se como questão crucial a ser desenvolvida. E o vinho, aliado a enogastronomia e às paisagens rurais apresentam-se como recursos estratégicos para a consolidação da atividade (Hall et al, 2004; Brow \& Getz, 2005; Nowak \& Newton, 2006; Bruwer \& Alant, 2009; Silva, Etges \& Valduga, 2016).

A paisagem, como recurso e elemento identitário de uma rota de vinhos, e sobretudo de uma rota que se desenvolve no meio rural, possui suma importância. Portanto, as vinícolas foram solicitadas a avaliar no questionário a importância dos recursos naturais, culturais e históricos que compõe a paisagem de uma rota de vinhos segundo critérios estabelecidos por Elias (2008) e Escolar \& Morueco (2011). Em uma escala crescente de importância de 1 a 7, a avaliação global da relevância da paisagem foi 6,2-um índice alto, porém esperado, tendo em vista que cinco das sete vinícolas estão em um meio rural de alto valor paisagístico. No quadro a seguir apresenta-se em ordem crescente de importância conforme a nota atribuída pelas vinícolas:

\section{Quadro 3: Importância dos elementos da paisagem segundo as vinícolas da VINOPAR.}

\begin{tabular}{|l|c|}
\hline $\begin{array}{l}\text { Na rota da Vinopar, que importância é atribuída aos seguintes elementos da } \\
\text { paisagem (escala de 1 a 7)? }\end{array}$ & Média \\
\hline Contaminação reduzida & 6 \\
\hline Instalações dos empreendimentos vinícolas & 5,8 \\
\hline Arquitetura & 5,4 \\
\hline Patrimônio histórico-cultural do roteiro & 5,4 \\
\hline Presença de restaurantes & 5 \\
\hline Presença de vinhedos & 4,4 \\
\hline Ações de sustentabilidade & 4,4 \\
\hline Sinalização do roteiro & 3 \\
\hline
\end{tabular}

Fonte: os autores (2018).

Observa-se que a contaminação reduzida é tida com maior preocupação, seguida das instalações das vinícolas, arquitetura e patrimônio histórico-cultural do roteiro. A presença de vinhedos não se mostra tão importante quanto os demais quesitos, uma vez que apenas duas das sete vinícolas possuem parreirais integrados à propriedade. As dificuldades climáticas seriam o fator que mais intimidaria a expansão da viticultura na RMC. Ainda que a presença de vinhedos seja um recurso legitimador agregando valor à experiência segundo a percepção do turista, conforme demonstrado por Lavandoski \& Lanzer (2008) e também no caso de Lanzarote destacado por González Morales, Ojeda \& Hernández Torres (2015), esta não 
se revelou como aspecto prioritário pelos empreendedores. Ainda, chama a atenção a baixa importância dada à sinalização do roteiro, uma vez que se considera crucial para a melhor orientação do turista e condição de constituição de uma rota propriamente dita (Álvarez García et al, 2014; ACEVIN, 2014).

Com a realização das entrevistas, somadas e confrontadas com as informações coletadas no grupo focal foi possível perceber as demandas coletivas da associação, cujos objetivos primordiais são assim descritos:

Fortalecer a produção e comercialização de vinhos finos, coloniais, espumantes e demais produtos da uva como sucos e grappas; estimular o consumo e a valorização de vinhos nacionais pelo consumidor brasileiro e estrangeiro; consolidar o Paraná como um novo polo vitivinicultor no cenário nacional e estimular a prática do enoturismo despertando experiências e estímulos diversos aos amantes do vinho, da gastronomia e das paisagens rurais da região metropolitana de Curitiba. (VINOPAR, 2016; 2018).

Sobre as expectativas das vinícolas quanto ao papel da organização, as vinícolas foram indagadas sobre a o grau de importância e de urgência de ações estratégias de gestão divididas em cinco grandes áreas: (1) aspectos institucionais e organização; (2) informação, sinalização e comunicação; (3) criação de novos produtos; (4) demanda e comercialização; e (5) formação. A cada uma destas áreas, foi solicitado que as vinícolas ponderassem o grau de importância de 1 a 7 e o grau de urgência de 1 a 3 . A partir da soma simples destes índices seguido da média geral das respostas foi possível a construção do quadro sobre as prioridades de execução e governança da VINOPAR, dais quais escolheu-se detalhar apenas aquelas cuja média é superior a 8 , conforme o quadro 4 :

\section{Quadro 4: Prioridades de ação da VINOPAR.}

\begin{tabular}{|c|c|}
\hline Área e subárea de ação & $\begin{array}{c}\text { Prioridade } \\
\text { (escala de } 1 \text { a 10) }\end{array}$ \\
\hline 1. Aspectos intitucionais e organização & 8,43 \\
\hline 1.1 Elaboração de um plano estratégico para desenvolvimento da VINOPAR & 9,62 \\
\hline 1.2 Elaboração de um cluster enoturístico na RMC & 8,37 \\
\hline 1.3 Criação de una gerencia executiva para a VINOPAR & 9,25 \\
\hline 1.4 Colaboração com o trade turístico e desenvolvimento de ações conjuntas & 9,13 \\
\hline $\begin{array}{l}\text { 1.5 Firmar acordos com instituições turísticas e culturais para desenvolvimento de } \\
\text { ações conjuntas }\end{array}$ & 8,25 \\
\hline 1.6 Firmar acordos de colaboração com os municípios da RMC sede das vinícolas & 8,25 \\
\hline 1.7 Criação de uma base de dados comum da VINOPAR & 8,25 \\
\hline 2. Informação, sinalização e comunicação & 8,34 \\
\hline 2.1 Criação e difusão de imagem corporativa atrativa & 8,88 \\
\hline 2.2 Criação e gestão de página web da VINOPAR & 9,5 \\
\hline 2.3 Uso das redes sociais para promoção da VINOPAR & 8,63 \\
\hline 2.4 Desenvolvimento de plano de sinalização homogêneo da rota & 8,13 \\
\hline 2.5 Desenvolvimento de sistema de geolocalização das vinícolas na web & 8,88 \\
\hline 3. CRIAÇÃO DE NOVOS PRODUTOS & 6,78 \\
\hline 1.3 Criação de uma loja online para produtos enológicos, gastronômicos e turísticos & 8,13 \\
\hline 4. Demanda e comercialização* & 7,44 \\
\hline 5. Formação & 8,54 \\
\hline 5.1 Firmar acordos de formação com a universidade & 9 \\
\hline 5.2 Firmar convênios de estágios com alunos de turismo e gastronomia & 8,88 \\
\hline 5.3 Estímulo a realização de pesquisas de pós graduação sobre as vinícolas da região & 8,13 \\
\hline 5.4 Desenvolvimento de projetos de pesquisa em conjunto & 8,13 \\
\hline
\end{tabular}

Fonte: os autores (2018).

* Não obteve média mínima 8 em nenhum dos quesitos, portanto, não foi detalhado. 
Na primeira área, aspectos institucionais e de organização, destaca-se a realização de um plano estratégico conjunto, a criação de uma gerencia executiva ${ }^{2}$ e de acordos com distintas instituições para ações conjuntas. Isso deixa clara a preocupação em dar uma maior formalização e capacidade de gestão à VINOPAR, conforme foi confirmado pelas respostas obtidas no grupo focal. A estas ações seguem em importância firmar acordos com empresas turísticas e municípios, a formação de um cluster e de uma base de dados comum da VINOPAR que permita inclusive uma maior familiarização entre as vinícolas que compõe a associação. Trata-se de ação fundamental para a cooperação em enoturismo e seu fortalecimento territorial (Tomazzoni, Valduga \& Ashton, 2016; Salvagni, Valduga \& Nodari, 2017).

$\mathrm{Na}$ segunda área, informação, sinalização e comunicações, destaca-se a criação e gestão de uma página web da VINOPAR, que evidencie a marca institucional e figure o recurso de geolocalização das vinícolas ${ }^{3}$. Isto sugere a importância que os empresários atribuem à tecnologia e à internet como ferramenta eficiente de comunicação para o enoturismo. A criação de um recurso de geolocalização das vinícolas seria uma resposta frente à dispersão territorial das mesmas, facilitando assim o acesso de seus visitantes (Leiper \& Carlsen, 1998; Getz, 2000; Lavandoski et al, 2017).

A terceira área, criação de novos produtos, não mereceu tanta atenção entre os representantes das vinícolas. Apesar de existência de temas que vão de encontro a considerações da ACEVIN como a criação de um centro de interpretação do vinho ou de produtos corporativos sob a marca VINOPAR, estes não foram avaliados como prioritários. Somente a criação de uma loja on line com seus produtos mereceu uma qualificação notável, porém dita ação é controversa em virtude das diferentes reações durante o grupo focal. Possíveis explicações ao baixo interesse nesta área, deve-se talvez às vinícolas considerarem adequada sua oferta atual de produtos de enoturismo (vide quadro 2) bem como a maneira individualizada como é ofertada. A oferta de novos produtos relacionados com o vinho, a gastronomia e outros aspectos culturais a ela relacionados, através de um centro de interpretação por exemplo, consolidariam e ajudariam a expansão deste projeto ao diversificar suas possibilidades (Bruwer \& Alant, 2009; Silva, Etges \& Valduga, 2016; Salvado, 2017)

A área que menos interessou as vinícolas foi sobre medidas de demanda e comercialização. Não houve nenhuma ação proposta que alcançasse pontuação notável, salvo a participação em feiras e eventos gastronômicos e turísticos, com média 7,88. Tal desinteresse deve-se possivelmente aos baixos volumes de produção da maioria das vinícolas - que se tornariam insuficientes em caso de grande demanda - e dos altos custos e encargos tributários decorrentes de uma política de comercialização em escala nacional, por exemplo.

Por último, a área de formação consta como a mais valorizada, o que demonstra um interesse da associação em obter apoio de universidades, seja por meio de cursos de formação, seja na oferta de estagiários para atuar nas vinícolas, vislumbrando um encaminhamento futuro daqueles que se destaquem e queiram se aprofundar na área. Evidencia-se aqui o papel sensibilizador que a própria pesquisa repercutiu nas vinícolas, quando elas passam a reconhecer a oportunidade de trabalhar com estudantes de turismo e gastronomia em seus empreendimentos.

\section{A caraterização dos enoturistas da RMC e sua percepção das vinícolas}

Este tópico estrutura-se em dois momentos: a caracterização do perfil dos turistas feita a partir dos questionários respondidos pelas vinícolas e a percepção destes turistas a partir de análise de comentários e de imagens adicionadas na plataforma TripAdvisor.

O número médio mensal de visitantes apontadas pelas respondentes é de 530 sendo a maioria brasileiros provenientes de Curitiba e região metropolitana (50\%) seguido de São Paulo (16,7\%) e o restante de outros estados como Rio de Janeiro, Minas Gerais e em menor escala de outros estados do sul, nordeste e norte do país. Quanto aos estrangeiros, representam uma minoria, provenientes de Inglaterra, EUA, Alemanha, Holanda e América Latina.

Segundo as vinícolas, as visitas nunca se realizam com visitantes sós, mas aqueles que fazem em família (48\%), entre amigos $(28,7 \%)$, casais $(21,3 \%)$ e grupos de turistas de negócios em viagens de incentivo (6\%). Sobre a época do ano em que as visitas são realizadas não foi observada sazonalidade. Os meses de março a maio concentram a maioria dos visitantes $(37,9 \%)$ época que coincide com o fim da colheita e o início do outono. As visitas de junho a agosto - período invernal - representam $25 \%$, seguido pelos meses de primavera, setembro a novembro (21\%) e com menor incidência durante o verão, de dezembro a fevereiro (17\%), quando supõe-se que os turistas busquem mais atividades relacionadas ao sol e praia. 
Quanto aos gastos médios, eles variam conforme a atividade da qual participam sendo o valor mais alto nas festas da vindima ( $\mathrm{R} \$ 175,00)$, seguido de compras de vinhos e souvenires $(\mathrm{R} \$ 155,00)$, eventos gastronômicos $(\mathrm{R} \$ 150,00)$, alimentos e bebidas nos restaurantes $(\mathrm{R} \$ 100,00)$ e degustações e visitas guiadas $(\mathrm{R} \$ 65,00)$. Eventos como festas das vindimas são fundamentais para oferecer a oportunidade de enoturistas conhecerem os produtos, conforme apontam Galvéz, Fernández \& Lopez-Guzmán (2015).

A estadia por mais de um dia restringe-se a casos pontuais na vinícola Araucária por esta contar com duas cabanas em meio ao bosque. A quase totalidade reside ou hospeda-se na capital Curitiba. Eventos de confraternização surgem com a demanda de empresas e associações profissionais e correspondem a 28,6\% do total, nas vinícolas que possuem estrutura de alimentação, sobretudo nas vinícolas Araucária, Franco Italiano e Cave Colina de Pedra. Casamentos e formaturas nestes restaurantes também são realizados esporadicamente (17\%).

A seguir a análise dos comentários e das imagens informadas pelos turistas na rede social de informações a viajantes TripAdvisor. Os dados são vistos sob a ótica da experiência em enoturismo (Manosso et al, 2016) destacando os aspectos positivos, negativos e os mais valorizados em uma visita à vinícola.

Fotografias e comentários foram classificados por temas seguindo critérios de pesquisas anteriores feitas em regiões com enoturismo consolidado (Chartes \& Ali Knight, 2002; Alant \& Bruwer, 2004; Áurea Vieira et al, 2013; Ricolfe, Barrio \& Vera, 2010, Manosso et al, 2016) e atendendo aos objetivos desta investigação. Tratou-se de organizar os dados em grupos iguais ou similares, ainda que nem sempre possível já que temas como a "hospitalidade/atendimento" ou o "aprendizado" não são propriamente "fotografáveis" ou o são de maneira escassa.

O quadro 5 apresenta a síntese em porcentagem dos 483 comentários e 550 fotografias analisados de cinco vinícolas que possuíam o perfil ativo no Trip Advisor. As categorias estão em ordem de incidência totais:

\section{Quadro 5: Porcentagem de comentários e fotos do TripAdvisor agrupados por categoria}

\begin{tabular}{|l|c|c|}
\hline \multicolumn{1}{|c|}{ Tema/Categoria } & \% de Comentários & \% de Fotografias \\
\hline Visita guiada & 9,6 & 26,2 \\
\hline Paisagem & 11,3 & 24 \\
\hline Hospitalidade/atendimento & 33,4 & 0 \\
\hline Gastronomia & 19,4 & 9,9 \\
\hline Degustação de vinhos & 13,3 & 11,3 \\
\hline Arquitetura/decoração & 4 & 17,3 \\
\hline Instalações & 2,6 & 11,3 \\
\hline Aprendizado & 2,9 & 0 \\
\hline Acessos/Sinalização & 2 & 0 \\
\hline Total & 100 & 100 \\
\hline
\end{tabular}

Fonte: os autores (2018)

Como demonstra o quadro 5, a maioria dos comentários dirige-se aos anfitriões, que exercem forte influencia na percepção da qualidade da experiência turística como agentes de hospitalidade: "atendimento" e "visita guiada" somam mais de 40\% dos comentários. A gastronomia e os vinhos são também dois componentes basilares da qualidade da experiência do enoturismo, respondendo por 19\% e 13\% dos comentários sobre as vinícolas. "Comer e beber bem" são condições sine qua non do enoturismo (Hall et al, 2004; Brow \& Getz, 2005; Bruwer \& Alant, 2009; Silva, Etges \& Valduga, 2016, Manosso et al, 2016). A arquitetura das vinícolas segue com $4 \%$, já o aprendizado adquirido durante a visita apesar de 2,9\% dos comentários é avaliado positivamente por todos, reforçando a experiência pela via do saber de muitos enoturistas. Por último, acessos/sinalização com $2 \%$, comentários focados na dificuldade de encontrar certas vinícolas ou a distância longa inesperada.

Mais de um quarto das fotos encontradas, em ambientes exteriores e interiores, reforçam o protagonismo da "visita guiada" às vinícolas da Vinopar (26\%), com fotos frequentes dos anfitriões, muitos deles proprietários. O caráter "familiar" das vinícolas é um valor apreciado. A paisagem segue com quantidade 
similar de imagens destacando o meio ambiente rural do entorno, a cultura agrícola - viticultura, e elementos que simbolizam à natureza. Observa-se, portanto, que a experiência em enoturismo tem como pilares a visita guiada e a paisagem, também manifesta nas fotos de arquitetura, que segue em quantidade fotografada (17\%). As instalações vinícolas, por sua vez, concentram $11,3 \%$ das imagens e a enogastronomia - com fotos de vinhos e comida, somam mais de $20 \%$ intensificando a dimensão do prazer, expressa em comer e beber bem. Embora os proprietários não estimem tanto valor ao contexto paisagístico, pelas fotografias ele fica evidente e é fator fundamental como atesta a literatura (Elías, 2008; Lavandoski \& Lanzer, 2008; Escolar e Morueco, 2011; Falcade, 2011; Sequeira \& Diniz, 2011; Álvarez García et al, 2014; Gravari-Barbas, 2014; González Morales, Ojeda \& Hernández Torres, 2015).

A ampla maioria das avaliações gerais (98\%) e comentários (93\%) são positivos. Os escassos comentários negativos (7\%) são decorrentes de dificuldades de acesso (38\% deste total), da gastronomia (24\%) e de contatos de serviço - "atendimento" (21\%). De forma geral, os dados coincidem com o observado em estudos de comportamento de demanda mencionados realizados na Austrália, Nova Zelândia e Espanha.

\section{Considerações finais}

O presente artigo buscou caracterizar o surgimento e a oferta de um novo polo de enoturismo situado na RMC, paralelo a criação da associação de produtores desta região - a VINOPAR, e elencar os desafios e expectativas de gestão e governança percebido pelas suas vinícolas integrantes. Adicionalmente foi realizado um breve descritivo do perfil da demanda de visitantes existente e, através da análise de imagens e comentários da plataforma digital TripAdvisor, foi possível perceber quais atributos são mais valorizados pelos enoturistas.

Constatou-se que as vinícolas integrantes constituem um grupo heterogêneo quanto a antiguidade, volume de produção e oferta de estruturas de apoio ao enoturismo, mas que estão inseridas em sua maioria em entorno rural de alto valor agregado, o que reforça o papel da paisagem como agregador da experiência. A dispersão territorial somada a falta de sinalização e dificuldades de acesso em alguns casos dificultam a consolidação enquanto uma rota do vinho. Visto que a maioria é de gestão familiar e concentram a venda de produtos diretamente na propriedade, o enoturismo revela-se crucial para a prospecção comercial destas vinícolas. Observou-se que algumas medidas foram implementadas desde a fundação da associação, como a criação de uma marca coletiva e de um guia ilustrativo da oferta de enoturismo da região.

Importante ressaltar que os problemas que mais preocupam aos responsáveis de empresas que compõe VINOPAR, são referentes a "formação", "institucionais e de organização". A construção de uma página web e da contratação de um secretário executivo, ambas ações tidas como prioritárias durante a pesquisa, se concretizaram posteriormente e demostram que a VINOPAR vislumbra objetivos coletivos de fato. A prioridade seguinte sobre "informação, sinalização e comunicação" demonstram um aspecto carente da rota. E por último, questões de "demanda e comercialização" e de "criação de novos produtos" ainda não são prioritárias.

Entende-se, portanto, que a VINOPAR antes de ampliar seu marco de atuações mediante campanhas de promoção e criação de novos produtos, deve consolidar o projeto mediante a preparação de seus recursos humanos e a melhoria de sua organização e capacidade de gestão, assim como sua imagem e comunicação.

Finalmente, as análises do perfil de demanda permitiram identificar que excursionistas da capital Curitiba são os principais usuários desta oferta de enoturismo regional. Seus gastos distribuem-se entre a participação de eventos do calendário da vitivinicultura, visitas guiadas e experiências enogastronômicas. A análise dos comentários e imagens permitiu exacerbar o valor dado à hospitalidade dos anfitriões, às visitas guiadas conduzidas pelos proprietários das vinícolas e o entorno paisagístico onde estas se desenrolam. Somados à qualidade da enogastronomia oferecida, estas são percebidas como destaques da experiência em enoturismo e de fato, parte substancial da mesma.

Os autores agradecem a Fundación Carolina pelo financiamento da pesquisa e ao CNPq através do projeto $\mathrm{n}^{\circ} 303570 / 2017-2$.

\section{Bibliografia}

ACEVIN, Associación Española de Ciudades del Vino. 2014. Prescripciones técnicas y solicitud de ofertas para la selección de la empresa encargada de la realización de las auditorías de certificación y renovación de la certificación de las rutas del vino del club de producto rutas del vino de españa en 2015 - 2016: pp. 1-8. Disponível em www.acevin.es 
Alant, K.; Bruwer, J. 2004. Wine tourism behaviour in the context of a motivational framework for wine regions and cellar doors. Journal of Wine Research, 15(1): 25-35.

Alonso, A. D.; Sheridan, L.; Scherres, P. 2008. "Importance of tasting room for Canary Island's wineries". British Food Journal 110(10): 977-988.

Alonso, A. D. 2009. "Wine, tourism and experience in the Canary Islands context". Tourism: An International Interdisciplinary Journal 57(1): 7-27.

Alonso, A. D.; Liu, Y. 2011. "The potential for marrying local gastronomy and wine: the case of the fortunate islands". International Journal of Hospitality Management 30: 974-981.

Alonso, A. D. Liu, Y. 2012. "The challenges of the Canary Islands wine sector and its implications: a longitudinal study". Pasos, Revista de Turismo y Patrimonio Cultural 10(3): 345-355.

Ali-Knight, J.; Carlsen, J. 2003. "An exploration of the use of 'extraordinary' experiences in wine tourism". In: Lockshin, L; Rungie, C. (EDS). Proceedings of the International Colloquium in Wine Marketing. Wine Marketing Group. University of South Australia. Adelaide.

Álvarez García, José, del Río Rama, María de la Cruz, Coca Pérez, José Luís, \& González Sanmartín, Juan Manuel. 2014. "Turismo enólogico y ruta del vino del ribeiro en Galicia-España”. Estudios y perspectivas en turismo, 23(4), 706-729

Asero, V.; Patti, S. 2009. "From wine production to wine tourism experience: the case of Italy". American Association of Wine Economists - AAWE Working. Paper 52.

Baptista, B. 2008. "La temprana vitivinicultura en Uruguay: surgimiento y consolidación (1870-1930)". América Latina en la historia económica, (29), 99-129.

Bizinelli, C.; Manosso, F.; Gimenes-Minasse, M. E. S. G.; Souza, S. do R.; 2014. "Enoturismo e Turismo de Experiência: novas possibilidades para a inclusão de pessoas com deficiência visual: Vinícola Dezem (Toledo, Paraná, Brasil)". Turismo e Sociedade, Curitiba, v. 7, n. 3, p. 495-522.

Brandenburg, A. 2018. Turismo rural: seus efeitos e sua relação com a ruralidade da colônia mergulhão em São José dos Pinhais-PR. Mundo Rural e Ruralidades. Curitiba: Editora UFPR, 2018.

Briones Quiroz, F. 2006. "Los inmigrantes franceses y la viticultura en Chile: El caso de René F. Le Feuvre". Universum (Talca), 21(2), 126-136.

Brown, G.; Getz, D. 2005. "Linking wine preferences to the choice of wine tourism destinations". Journal of Travel Research, 43, p. 266-276.

Bruwer, J. 2003. "South African wine routes: some perspectives on the wine tourism industry's structural dimensions and wine tourism product". Tourism Management 24: 423-435.

Bruwer, J.; E Alant, K. 2009. "The hedonic nature of wine tourism consumption: an experiential view". International Journal of Wine Business Research 21(3), p. 235-257.

Carlsen, J. 2004. "A Review of Global Wine Tourism Research". Journal of Wine Research. Volume 15, Issue 1.

Carmichael, B.; A. 2005. "Understanding the wine tourism experience for winery visitors in the Niagara Region, Ontario, Canada”. Tourism Geographies, Vol. 7 No. 2, pp. 185-204.

Capitello, R.; Begalli, D.; Agnoli, L. 2013. "A new approach to the analysis of the visitor perceptions for a destination: the role of food and wine experiences". Scientific Papers Series Management, Economic Engineering in Agriculture and Rural Development, 13(1).

Charters, S., \& Ali-Knight, J. 2002. Who is the wine tourist?. Tourism management, 23(3), 311-319.

COMEC - Coordenação da Região Metropolitana de Curitiba. 2017. Região Metropolitana de Curitiba. Revista COMEC. Disponível em www.comec.pr.gov.br

Díaz Armas, R. 2008. "Potencialidad e integración del 'turismo del vino' en un destino de sol y playa: el caso de Tenerife". PASOS, Revista de Turismo y Patrimonio Cultural, 6 (2es), 199-212.

Castro, V., Santos, G., Gimenes-Minasse, M. H., \& Giraldi, J. 2017. "Práticas de visitação nas vinícolas da Serra Gaúcha: unindo vitivinicultura e turismo no sul do Brasil". Revista Turismo Em Análise, 28(3), 380-402.

del Río Rama, M.C.; Álvarez García, J.; Vila Alonso, M.; Iglesias González, L. 2013. Turismo enológico y ruta del vino del Bierzo. Revista Digital de Marketing Aplicado. 11(2), p. 185-212.

Elías, L. 2008. "Paisaje del viñedo: patrimonio y recurso". PASOS. Revista de Turismo y Patrimonio Cultural, 6 (2es), 137-158.

Escolar, B.M., Morueco, R.F. 2011. Vino, turismo e innovación: las rutas del vino de España, una estrategia integrada de desarrollo rural. Estudios de Economía Aplicada, 29(1), p. 129-144.

Féder, E. M. S. V.; 2005. Santa Felicidade (Curitiba, Paraná): na polenta, uma história de hospitalidade. Dissertação de mestrado, Mestrado em Turismo e Hotelaria, Universidade do Vale do Itajaí. 
Feger, J. E.; Souza Junior, S. V.; Gândara, J. M. G. 2016. "Análise da reputação online do destino turístico Lapa (Paraná): uma aplicação do método TOURQUAL para análise da qualidade em serviços”. Revista Iberoamericana de Turismo, v. 6, p. 138-156.

Fuller, P. 1997. "Value adding the regional wine experience". Australian e New Zealand Wine Industry Journal 12(1): 35-39.

Gabardo, W., Valduga, V. 2017. Colher e pisar a uva: encenação da tradição para o enoturismo. O caso da Festa da Vindima da Vinícola Araucária,/Paraná/Brasil. In: Anais. X Congresso Brasileiro de Turismo Rural. UFSM, Santa Maria.

Gálvez, J. C. P., Fernández, G. A. M., \& Guzmán, T. L. G. 2015. "Motivación y satisfacción turística en los festivales del vino: XXXI ed. cata del vino Montilla-Moriles, España”. Tourism \& Management Studies, 11(2), 7-13

Getz, D.; Dowling, R.; Carlsen, J.; Anderson, D. 1999. "Critical success factors for wine tourism". International Journal of Wine Marketing, 11(3), p. 20 - 43.

Getz, D. 2000. Explore Wine Tourism: Management, Development and Destinations. New York: Cognizant Communication Corporation.

González Morales, A., \& Ojeda, A., \& Hernández Torres, S. 2015. "El Cultivo Del Viñedo Como Recurso Turístico Cultural: El Caso de La Geria (Lanzarote. Islas Canarias, España)”. Papeles de Geografía, (61), 109-121.

Gravari-Barbas, M. 2014. "Winescapes : tourisme et artialisation, entre le local et le global", Cultur: Revista de Cultura e Turismo, 8(3).

Cooperative Hierarchies, London,

Guthey, G.T.; 2008. "Agro-industrial conventions: some evidence from northern California's wine industry". Geographical Journal 174, 138-148.

Hall, C. M.; Sharples, L.; Cambourne, B.; MacioniS, N. 2004. Wine tourism around the world: development, management and market. Oxford, Hardcover.

Hall, C. M. 2009. "Innovation and tourism policy in Australia and New Zealand: never the twain shall meet?" Journal of Policy Research in Tourism, Leisure and Events, 1(1), 2-18.

Hojman, D. E.; Jones, P. H. 2012. "Wine tourism: Chilean wine regions and routes". Journal of Business Research 65(1), p. 13-21.

Lacoste, P. 2013. Vinos de capa y espada: 300 años de vitivinicultura y economía en Mendoza y San Juan. Santiago de Chile: Editorial Antucurá.

Lacoste, P.; Aranda, M; Gaete, J. 2011. Pisada de la uva y lagar tradicional en Chile y Argentina (1550-1850). Atenea 503, 39-81.

Lavandoski, J., \& Lanzer, R. 2008. "Percepção da Paisagem: Uma análise a partir de fotografias do Vale dos Vinhedos", RS. Seminário de pesquisa em turismo do Mercosul, SeminTUR, 5, 1-15.

Lavandoski, J., Silva, J. A. da, Vargas-Sánchez, A., Santos Pinto, P. S. L. 2017. "Indutores e efeitos do desenvolvimento do enoturismo nas vinícolas: a perspectiva das capacidades dinâmicas". Turismo, Visão e Ação, v. 19, n. 3, p. 458-486.

Leiper, N.; Carlsen, J. 1998. Strategies for winery managers contemplating tourism markets. A case history: What happened to a winery positioned to remain on the fringe? In: R. Dowling, R.; Carlsen, J. (Org) Wine Tourism: Perfect Partners. Proceedings of the First Australian Wine Tourism Conference. Margaret River, Western Australia. Bureau of Tourism Research.

López-Guzmán, T; García, J.R.; Rodríguez, A.V. 2013. Revisión de la literatura científica sobre enoturismo en España. Cuadernos de Turismo, 32, 171-188.

López-Guzmán; Cañizares, S.M.S. 2008. La creación de productos turísticos utilizando rutas enológicas. PASOS. Revista de Turismo y Patrimonio Cultural, 6(2), p. 159-171.

Manosso, F. C., Silva, D. S., Bizinelli, C. \& Gândara, J. M. 2016. Relações de consumo nas experiências enoturísticas: uma análise a partir de empreendimentos hoteleiros vinoterápicos. Tourism and Hospitality International Journal, 6 (2), 107 - 125.

Marzo Navarro, M.; Pedraja Iglesias, M. 2012. "Critical factors of wine tourism: incentives and barriers from the potential tourist's perspective". International Journal of Contemporary Hospitality Management, 24(2): p. 312-334.

Matellanes Lazo, M. 2014. "Social media en el sector del enoturismo". Revista de Comunicación de la SEECI, (34), 347-49.

Medina, F.X.; Tresserras, J. 2008. Turismo enológico y rutas del vino en Cataluña. Análisis de casos: D.O. Penedès, D.O. Priorat y D.O. Montsant. PASOS. Revista de Turismo y Patrimonio Cultural, 6(3), p. 493-509. 
Ministério do Turismo. 2013. Categorização dos municípios das regiões turísticas do mapa do turismo brasileiro. pp. 18-20. Disponível em www.turismo.gov.br

Mitchell, R.; Hall, M. 2006. Wine tourism research: the state of play. Tourism Review International, 9, p. 307-332.

Nowak, L. I.; Newton, S. K. 2006. "Using the tasting room experience to create loyal customers". International Journal of Wine Marketing, Vol. 18 No. 3, pp. 157-65.

Paglod, A. 2011. Las condiciones para el desarrollo de enoturismo en la provincia de Mendoza, Argentina. In: Territorios expuestos y processos culturales. Hoyos, Czerny e Cadena. Universidad Autónoma del Estado del México y Universidad de Varsovia, Polonia.

Pine II, B. J.; Gilmore, J. H. 1998. "Welcome to the experience economy". Harvard Business Review.

Quadri-Felitti, D.; Fiore, A. M. 2012. "Experience economy constructs as a framework for understanding wine tourism". Journal of Vacation Marketing, 18(1): p. 3 -15.

Ricolfe, J. S. C.; Barrio, J. E. R.; Vera, J. M. B. 2010. Análisis del mercado potencial enoturístico en Valencia. Papers de Turisme, 6 (47-48), p. 93-108.

Rodríguez, Á. V., López-Guzmán, T., \& García, J. R. 2013. "Análisis del enoturista en la Denominación de Origen del Jerez-Xérès-Sherry (España)”. Tourism \& Management Studies, 9(2), 37-43.

Roberts, L.; Sparks, B. 2006. Enhancing the wine tourism experience: the customers viewpoint. In: Carlsen, J.; Charters S. (Eds). Global Wine Tourism: Research, Management \& Marketing. CAB International, Cambridge, pp. 47-55.

Sanders, D. 2004. Wine tourism and regional development: a case study of the Margaret River wine region - Western Australia. In: J. Carlsen, J.; Charters, S. (Org) International Wine Tourism. International Wine Tourism Conference, Margaret River, Western Australia, Perth: Vineyard Publications.

Salvado, J. O. 2017. "Boticas e o 'Vinho dos Mortos': reforçar a identidade cultural do território na experiência de enoturismo". Revista Brasileira de Pesquisa em Turismo, v. 11, n. 2, p. 294-319, 2017.

Salvagni, J, Valduga, V; Nodari, C. 2017. "Cooperação como propulsora da inovação em turismo na região Uva e Vinho do Rio Grande do Sul, Brasil”. Otra Economía, v. 10, p. 253-262

Sánchez, J.A.L. 2010. Posibilidades de desarrollo del enoturismo en la denominación de origen Jerez-Xerry-Sherry y Manzanilla de Sanlucar de Barrameda y vinagre de Jerez. Boletín de la Asociación de Geógrafos Españoles, 53, p. 21-41.

Sartori, A., Mottironi, C.; Corigliano, M. 2012. "Tourist destination brand equity and internal stakeholders: an empirical research". Journal of Vacation Marketing, Vol. 18, No. 4, pp. 327-340.

Sequeira, T., \& Diniz, F. 2011. "Desenvolvimento e território: o caso do cluster do Vinho do Porto". Revista Portuguesa de Estudos Regionais, (25-26), 95-106.

Silva, R.N., Etges, V.E. \& Valduga, V. 2016. "A enogastronomia como produto turístico: dinâmicas territoriais no vale dos vinhedos - RS/Brasil". Tourism and Hospitality International Journal, 6(2), 42-57.

Silva, F. F. de A. 2016. "Enoturistas no Chile: segmentação e comportamento". Revista Turismo em Análise, v. 27, n. 3.

Silva, D. S.; Gândara, J. M. 2016. "Reputação online dos Spas de Foz do Iguaçu, PR, Brasil”. Marketing \& Tourism Review, v. 1, p. 1-30.

Silva, S. R. X.; Lacay, M. C., Gândara, J. M. G. 2018. "Espaço: entre a reputação online e a compreensão dos visitantes e visitados na praça Santos Andrade, Curitiba-Brasil”. Marketing \& Tourism Review, v. 3, p. 01-31.

Simeon, R.; Sayeed, L. 2011. "Examining the online wine tourism experience of California wineries". International Journal of Online Marketing, 1(1): p. 24-40.

SIMEPAR, Sistema Meteorológico do Paraná. 2018. Boletim climático 2017-2018. Disponível em http:// www.simepar.br/prognozweb/simepar/timeline/boletim_climatologico

Tomazzoni, E. L., Valduga, V., Ashton, M. S. G. 2016. "A Cooperação Técnica Internacional em Enoturismo na Região Uva e Vinho, Serra Gaúcha, Brasil”. Revista Latino-Americana de Turismologia, v. 2, n. 1, p. 31-43, 2016.

Tonini, H., \& Lavandoski, J. 2011. "Enoturismo: experiências e sensações no Vale dos Vinhedos (RS)". Revista Turismo Em Análise, 22(1), 25-43.

Valduga, V. 2014. "El enoturismo en Brasil: Un análisis territorial en el Estado de Rio Grande do Sul (Brasil) desde 1870 hasta 1970". Estudios y Perspectivas en Turismo, 23(2), 278-304.

UNESCO, United Nations Educational, Scientific and Cultural Organization. 2013. Mediterranean diet. Nomination file no. 00884 for inscription in 2013 on the Representative List of the Intangible Cultural Heritage of Humanity. Disponível em: https://ich.unesco.org/en/RL/mediterranean-diet-00884 
Williams, P. 2001. "The evolving images of wine tourism destination". Tourism Recreational Research, no 26(2), p. 3-10.

\section{Notas}

1 A criação da página web ocorreu após a realização da pesquisa com as vinícolas. Conforme será visto adiante, constituía umas das prioridades de ação da VINOPAR segundo as informações analisadas pelos autores

2 A contratação de um secretário executivo viria a confirmar-se em 2018, ano seguinte a realização da pesquisa, o que confirma o grau de importância e urgência desta ação atribuído pelas vinícolas.

3 A criação de uma página web para a associação viria a confirmar-se um ano após a realização das entrevistas, ainda sem recurso de geolocalização, porém com a marca coletiva da entidade em destaque. 